\title{
CEO SOB DESAFIO DUPLO: CRISE ECONÔMICA E INOVAÇÃO TECNOLÓGICA
}

\author{
CEO UNDER DUAL CHALLENGE: ECONOMY CRISIS AND TECH INNOVATION
}

Recebido em: 09/05/2018 - Aprovado em: 26/09/2018

Avaliado pelo sistema double blind review Editor Científico: Edson Sadao Iizuka DOI 10.13058/raep.2019.v20n1.1116

\section{MARCO F.SIMÕES-COELHO marco.simoes@coppead.ufrj.br \\ GISELA SENDER \\ RONALDO ANDRADE DECCAX \\ VICTOR MANOEL CUNHA DE ALMEIDA}

Universidade Federal do Rio de Janeiro

\section{RESUMO}

Este caso de ensino tem como questão central os desafios para a sobrevivência da empresa Ccaps Translation and Localization - empresa do segmento de localização de software, que é a adaptação de programas de computador para outros países, idiomas e culturas. O caso foi estruturado para desenvolver o conhecimento de alunos em cursos de graduação ou pós em Administração de Empresas e Engenharia de Produção, em particular nas disciplinas de estratégia e inovação. O caso possibilita que os alunos apreendam os conceitos fundamentais da Teoria da Inovação Disruptiva e da Ambidestria Organizacional. A primeira teoria descreve o impacto e desafios suscitados por inovações como as que ameaçam a sobrevivência da Ccaps e a segunda constitui instrumento estratégico para vislumbrar alternativas viáveis e promissoras para perenizar a empresa. Os alunos devem ser conduzidos pelo professor para a análise crítica dos ambientes competitivos e das capacidades atuais e futuras da Ccaps, explorando o caráter inibidor (problemas e restrições) e habilitador (soluções e "alavancas").

Palavras-chave: Estratégia; Inovação Disruptiva; Ambidestria Organizacional; Caso de Ensino; Tradução e Localização.

\begin{abstract}
This teaching case focuses on the challenges for the survival of the software localization company Ccaps Translation and Localization - localization of computer programs is to adapt them to different countries, languages, and cultures. The case was developed to target Business Administration and Production Engineering undergraduate or graduate students, particularly in the disciplines of strategy and innovation. The case allows students to apprehend the concepts of the Disruptive Innovation and the Organizational Ambidexterity theories. The former describes the impact and challenges that threaten Ccaps' survival while the latter is a strategic tool to reach promising and viable alternatives to maintain the company healthy in the long run. The professor should guide the students through the critical analysis of Ccaps' competitive environment and its current and future capabilities, exploring the inhibitor (problems and restrictions) as well as the enhancer (solutions and leverages) features.

Keywords: Strategy; Disruptive Innovation; Organizational Ambidexterity; Teaching Case; Translation and Localization.
\end{abstract}




\section{INTRODUÇÃO}

Ao longo dos 17 anos de existência da empresa, a Ccaps Translation and Localization - empresa do segmento de localização de software sediada no Rio de Janeiro - nunca havia enfrentado uma crise tão duradoura. Fabiano Cid, principal sócio e Diretor Executivo da Ccaps, acabava de ajustar uma apresentação com duras recomendações que levaria à reunião do Conselho Consultivo da companhia dali a pouco. $\mathrm{O}$ ano de 2016 continuava apontando para uma queda no faturamento, após dois anos difíceis, em que o Brasil entrara em uma das piores recessões de toda sua História. Ao mesmo tempo, a dramática mudança na tecnologia da indústria de localização mostrava que, mesmo quando a crise amainasse, outros desafios teriam de ser enfrentados, com o contínuo avanço da tecnologia que afetava fortemente este mercado.

No dia anterior ele havia recebido uma má notícia adicional - um dos principais clientes da empresa comunicara a decisão de centralizar os serviços para o Brasil e América Latina, até então prestados pela Ccaps, em uma fornecedora concorrente global. Assim, a empresa perderia a sua terceira maior fonte de receita antes do final do ano. Outros clientes já haviam deixado de fazer trabalhos ou diminuído sua demanda, mas nenhum deles deste porte e com a possibilidade de impactar tanto o negócio.

Os sócios da Ccaps se orgulhavam de haver construído uma empresa sólida, com serviços de alta qualidade sobre uma base de absoluta seriedade empresarial. Fabiano se formara em Letras e já havia tido o sonho de seguir carreira de ator. Mas ele se realizou na construção de um negócio que era muito inovador nos anos 1990 e permanecera na empresa.

O Conselho da Ccaps, além do próprio Fabiano, era formado pelos diretores de Produção e de Administração e Finanças da empresa, um sócio-investidor e um conselheiro externo, advogado tributário. Este grupo era responsável por orientar as principais decisões e aprovar o orçamento da empresa. Nos últimos anos, o Conselho havia discutido e autorizado a demissão de um grupo de funcionários menos graduados e tomado outras medidas difíceis para equilibrar as finanças. Agora, deveria ajudar o Diretor 
Executivo a não só continuar enfrentando a queda de faturamento no curto prazo, mas também a repensar a estratégia da empresa para assegurar sua sobrevivência.

\section{O MERCADO DE LOCALIZAÇÃO ${ }^{1}$}

Desde o começo de suas operações, a Ccaps se dedicara à localização de software. O serviço de localização pode ser definido como o processo de adaptação de um produto ou conteúdo para um novo local ou mercado, com o objetivo de dar a ele a aparência de ter sido criado especificamente para este mercado, independentemente de sua língua, cultura ou formato de origem, e inclui os seguintes elementos:

- Modificação de conteúdo de acordo com os gostos e hábitos de consumo locais.

- Adaptação do design e do layout para exibir corretamente o texto traduzido.

- Conversão para requisitos locais (como moedas e unidades de medida).

- Utilização de formatos apropriados para datas, endereços e números de telefone.

- Cumprimento dos regulamentos e requisitos legais do país e mercado de destino.

Para isto, a indústria de localização conta com players de diferentes naturezas, tamanhos e focos de mercado. Os Language Service Providers (LSPs) são as empresas que adaptam produtos e serviços para consumo em mercados multilíngues. Os LSPs fornecem os serviços de localização tanto para tradução (textos escritos - como rótulos de produtos, programas de computador, websites, aplicativos de celular, documentação de software, contratos e comunicações de marketing) quanto para interpretação (informações trocadas por via oral em reuniões e conferências, conversas telefônicas, situações médicas e jurídicas, entre outros).

1 Website da principal associação do setor, a GALA (Globalization and Localization Association) e relatórios da Common Sense Advisory. 
Os LSPs são classificados pelo número de idiomas com que lidam. Fornecedores multilíngues (Multi-Language Vendors - MLVs) trabalham com muitos idiomas e mercados; fornecedores unilíngues (Single Language Vendors - SLVs) oferecem serviços em um único idioma de destino (podendo traduzir a partir de mais de um idioma). Em um mercado intermediário, formado mais recentemente, se encontram os fornecedores regionais (Regional Language Vendors - RLVs), que abrangem áreas regionais de línguas e mercados, como por exemplo, América Latina, Europa Oriental, Oriente Médio ou Ásia.

Grandes empresas de tecnologia, multinacionais que têm ampla necessidade de localização de seus produtos, geralmente contam com um time interno de funcionários dedicados a assegurar os requisitos da sua linguagem corporativa e internacionalização do produto desde a fase de desenvolvimento. Estes times internos normalmente terceirizam parte do trabalho para os LSPs, já que não seria eficiente manter grupos dedicados para localização de todos os idiomas e culturas onde as empresas operam.

Por exemplo, quando o software Windows, da Microsoft, foi lançado pela primeira vez no Brasil precisou ser adaptado para este mercado, tanto no que diz respeito aos comandos que aparecem nas telas e menus, quanto aos manuais e opções de ajuda. Realizar esta adaptação foi muito além de traduzir simplesmente o idioma, uma vez que, principalmente na parte visível no programa, as palavras e termos normalmente têm tamanhos diferentes, levando à necessidade de fazer ajustes nas caixas de texto e no layout. Por ocasião do lançamento posterior de novas versões do Windows, no entanto, a adaptação foi muito menor, uma vez que grande parte do conteúdo já havia sido localizado, restando, portanto, apenas pequenos ajustes incrementais. Com isso, a demanda por grandes serviços de localização tende a tornar-se decrescente à medida que grandes plataformas já estão consagradas no mercado.

Em tempos mais recentes, aplicativos para smartphones desenvolvidos fora do Brasil e oferecidos aqui geraram um novo tipo de demanda. Ao contrário do exemplo acima, estes são individualmente menores, porém 
existem em quantidade consideravelmente superior. O aplicativo do Uber é um exemplo: teve que ser localizado em vários lugares do mundo, não só no que diz respeito à tradução do idioma, mas aos mapas, meios de pagamento e às eventuais regras de cada mercado.

\section{TAMANHO DO MERCADO}

A indústria de serviços linguísticos constituía um mercado estimado em US\$ 38,16 bilhões em 2015, tendo crescido mais de $60 \%$ no período de 2009 a 2015, segundo dados da Common Sense Advisory (empresa de consultoria e avaliação do mercado especializada no setor), que apontam para uma projeção de chegar a um valor de cerca de US\$ 50 bilhões em 2019.

Apesar do crescimento do mercado global previsto para os anos seguintes, a percepção dos líderes da Ccaps era que o mercado brasileiro ia na contramão deste movimento, com uma nítida retração. Esta tendência refletia-se também na queda de cerca de $10 \%$ da participação da América Latina e Caribe em relação ao faturamento global no ano anterior, participação esta já bastante reduzida dentro do mercado mundial $(0,46 \%$ em 2014 para $0,42 \%$ em 2015). A principal razão desta contradição era a crise econômica instalada na região, que a fazia perder relevância em comparação aos demais mercados.

\section{EMPRESAS}

Mesmo participando com $0,42 \%$ do faturamento do mercado total, a América Latina possuía cerca de 5\% dos LSPs em 2015. Este percentual mais de dez vezes superior ao do faturamento indicava uma alta fragmentação do setor nesta região.

Globalmente, a maioria das empresas era pequena (cerca de $60 \%$ com 2 a 5 funcionários ${ }^{2}$ ) e utilizavam o trabalho de tradutores independentes, permitindo que o custo variasse de acordo com o volume de trabalho e, portanto, mantendo melhor controle sobre seus resultados financeiros. O gerenciamento do trabalho e o controle da qualidade eram geralmente internos, ficando a cargo de funcionários da empresa.

2 The Language Service Market, Relatório 2015 (Common Sense Advisory) 
Havia centenas de milhares de freelancers trabalhando com tradução em todo o mundo. Alguns trabalhavam para clientes diretos ou para fornecedores multi-idiomas, uma tendência que o diretor geral da Ccaps, Fabiano, acreditava ser crescente na indústria. Desta forma, eles representavam uma competição para as empresas locais ou regionais.

Depois de três anos (2012, 2013 e 2014) figurando entre as cinco maiores empresas de localização no ranking da América Latina da Common Sense Advisory, a Ccaps passou a ocupar a sétima posição em 2015, devido à queda de faturamento em reais de cerca de $25 \%$, associada a uma taxa de câmbio desfavorável. ${ }^{3}$

Empresas multinacionais também atuavam no Brasil, sendo a principal delas a Lionbridge, o maior LSP do mundo. Para fins de comparação, em 2013 a Lionbridge, companhia de capital aberto negociada na bolsa americana Nasdaq, faturou US\$ 490 milhões, enquanto a Ccaps, em um bom ano, teve receita de cerca de US\$ 1,82 milhão.

\section{O IMPACTO DA TECNOLOGIA}

A indústria de serviços linguísticos tem sido impulsionada pela inovação e há todo um setor de pesquisa e desenvolvimento dinâmico e robusto buscando soluções tecnológicas que resultem em melhores resultados na localização. Praticamente todos os profissionais do setor, desde tradutores até gerentes de projeto e diretores, já usavam alguma ferramenta tecnológica no seu trabalho diário em 2016.

Os tipos de ferramenta que mais influenciavam as mudanças no mercado de serviços linguísticos eram o Translation Management System (TMS) e a Machine Translation (MT).

O TMS controla, agiliza e acelera o fluxo de trabalho de tradução e também pode ser conhecido como Globalization Management System ou Global Content Management System. O TMS pode ser tão simples como um portal web para transferir conteúdo entre a organização cliente e seus fornecedores de serviços linguísticos, mas pode também chegar a ser um sis-

3 The Language Services Market, Relatórios 2010, 2011, 2012, 2014 e 2015 (Common Sense Advisory) 
tema complexo abrangendo toda a empresa e automatizando a maioria das transferências de arquivos e comunicação no fluxo de trabalho entre clientes, empresas de localização, gerentes de projeto, tradutores, editores, revisores, equipe de controle de qualidade e outros.

Machine Translation (MT) é uma ferramenta de computação que, sem intervenção humana direta, traduz conteúdo para idiomas de destino, com base em algoritmos de computação. As ferramentas de MT oferecem velocidade e automação e podem ser usadas para traduzir grandes quantidades de informações, envolvendo milhões de palavras, em uma fração do tempo necessário para fazê-lo pelo método tradicional, com tradutores e revisores humanos. A qualidade de saída da MT pode variar consideravelmente, requerendo aprendizado constante da ferramenta no par de idiomas que esteja sendo localizado. A MT pode ser baseada em regras (Rule-Based Machine Translation) ou em modelos estatísticos (Statistical Machine Translation), ou seja, respectivamente, pode ser composta de algoritmos inteligentes baseados em gramática, sintaxe e outras regras ou da correspondência de padrões com vastas quantidades de textos de referência para encontrar traduções estatisticamente mais prováveis. O uso da Machine Translation frequentemente associa-se à pós-edição humana para uma melhor precisão do resultado, principalmente quando se requer um alto grau de qualidade e confiabilidade nos conteúdos localizados. À medida que os computadores se tornam mais poderosos e a capacidade de replicar as redes neurais humanas se torna realidade, a MT também se aproxima cada vez mais dos resultados alcançados por um tradutor humano.

\section{A CCAPS TRANSLATION AND LOCALIZATION}

No começo dos anos 1990, Fabiano imaginava seguir uma carreira no teatro, porém foi estudar Letras como uma ponte para seguir depois escrevendo textos literários além de atuar nos palcos. Logo ao deixar a faculdade ele chegou a escrever um romance, mas, para se manter financeiramente, começou a trabalhar como tradutor para um LSP brasileiro. Em 1996, mudou-se para Londres, com um contrato temporário de tradutor e lá permaneceu sempre atuando neste setor. Em 1999, definitivamente de volta 
ao Rio de Janeiro, Fabiano associou-se a um tradutor mais experiente e, juntos, formaram a Ccaps. Seu sócio, no entanto, logo recebeu um convite para uma posição atraente fora do Brasil e desligou-se da empresa. Fabiano decidiu continuar o negócio, buscando investimento que o permitisse montar uma estrutura básica, mas profissionalizada, para fornecer localização a alguns dos provedores multi-idiomas com os quais ele havia interagido durante sua experiência na Europa.

Em 2000, a Ccaps atraiu recursos de um investidor externo e começou sua trajetória como companhia de serviços linguísticos. Inicialmente, seu principal cliente foi uma das três maiores empresas globais do segmento de localização, que destinava boa parte do trabalho em português do Brasil para a empresa. A Ccaps aumentou a sua receita em quase sete vezes (563\%) entre 2000 e 2001, contratou seus primeiros funcionários e atingiu um patamar de operação que superou as expectativas de seu fundador. No entanto, o negócio permanecia muito dependente de seu primeiro e principal cliente, com cerca de $70 \%$ do faturamento vinculado a este grande player internacional.

Os acionistas entendiam que precisavam diminuir esta dependência e definiram duas estratégias para rapidamente alterar esta situação. A primeira foi oferecer serviços para todas as principais empresas internacionais do segmento, divulgando o profissionalismo e a alta qualidade do trabalho da Ccaps por meio de iniciativas de marketing direto, como palestras e patrocínio de sessões em eventos internacionais e de publicidade nos veículos globais da indústria de localização.

A segunda estratégia foi associar-se a outras empresas de localização do porte da Ccaps ao redor do mundo para, juntas, oferecerem trabalhos para clientes globais. Em conjunto com outras 15 empresas de diferentes países e dos cinco continentes, a Ccaps formou a Milengo, uma empresa sediada em Berlim, na Alemanha, com força de vendas na Europa e nos Estados Unidos. Cada associado prestava serviços na sua área geográfica e linguística e, juntos, competiam com os fornecedores multi-idioma de médio porte. 


\section{DIVERSIFICAÇÃO}

$\mathrm{Na}$ opinião de Fabiano, estas estratégias deram bons resultados e provaram-se acertadas, já que aquele cliente inicial da empresa decidiu se instalar no Brasil e deixou de contratar a Ccaps nos anos seguintes. A diversificação continuou e o número de clientes ativos da empresa passou a crescer continuamente desde 2002. Aos poucos, a Ccaps atingiu um novo patamar empresarial, com a criação de diretorias responsáveis pelas suas principais áreas, liberando Fabiano para trabalhar na estratégia e na internacionalização da empresa.

A Milengo foi relevante como força de vendas até 2009, quando esta parceria internacional deixou de dar resultados por problemas operacionais. Naquele momento, a Europa e os EUA passavam por dificuldades econômicas sérias e a América Latina ganhava dinamismo, assim como outros mercados emergentes. Os acionistas da Ccaps buscaram criar um novo modelo de negócio regional, com operação em português do Brasil e espanhol latino-americano. A empresa tornou-se então um fornecedor regional, ou RLV, buscando um novo patamar de clientes diretos com interesse neste mercado, estruturando também uma subsidiária nos EUA a fim de facilitar suas negociações com os clientes.

Para atrair os clientes diretos internacionais, o time da Ccaps desenvolveu uma franquia de eventos denominada "Think Latin America", que realizava encontros anuais em diferentes localidades (Brasil, EUA e Irlanda), além de coordenar um canal digital para discutir os negócios na região. Em 2014, a franquia foi vendida para a GALA (Globalization and Localization Association), que a multiplicou para diferentes regiões do planeta e áreas correlatas - tais como "Think India" e "Think Interpreting". A Ccaps permanecia como parte da Milengo até o final de 2016, mas sua participação se diluíra por frequentes aumentos de capital necessários para mantê-la funcionando e os resultados da sociedade eram diminutos.

\section{RECEITAS}

Ao final de 2013, a Ccaps atingia sua maturidade empresarial, com clientes diversificados, uma estrutura profissional com executivos seniores (porém 
relativamente cara para o setor), o maior nível de faturamento de sua história e um bom retorno financeiro. Mas, também neste momento, se iniciava uma grave crise econômica no Brasil e na América Latina, que impactou o interesse dos clientes pela região, diminuindo fortemente o volume de serviços.

A Ccaps alternou períodos de grande crescimento, como 2001/2002 ou 2008/2009, com uma certa acomodação no novo patamar nos anos seguintes. Até 2013, o nível de crescimento das receitas permitiu que a empresa seguisse investindo em qualificação e aumentando sua estrutura. No entanto, uma forte queda em 2014 obrigou a companhia a fazer seu primeiro ajuste significativo. Segundo Fabiano, "em 2014 tivemos de consumir toda a 'gordura' acumulada nos anos anteriores, o que ainda foi insuficiente. Tivemos que cortar uma série de atividades de promoção da empresa, viagens e nos vimos obrigados a eliminar $10 \%$ das posições funcionais."

\section{RECURSOS HUMANOS}

O número de funcionários em tempo integral da Ccaps cresceu consistentemente ao longo dos anos. Em 2013, a empresa atingira 25 funcionários em seus escritórios no Rio de Janeiro e em outras localidades, próximas aos principais clientes da empresa. Todos os funcionários eram profissionais com formação superior nas áreas-fim de linguística e engenharia de software ou suporte nas áreas de finanças ou vendas. Mensalmente, a Ccaps também mobilizava o trabalho de dezenas ou centenas de tradutores e engenheiros independentes que prestavam serviço não-exclusivo para a companhia a partir de suas bases, no Brasil ou no exterior.

Em termos de estrutura organizacional, reportando ao CEO havia três diretorias (uma das quais, Marketing e Vendas, também acumulada pelo CEO). Cada diretor tinha sua equipe de gerentes ou coordenadores, que geriam o trabalho interno ou subcontratavam outras empresas e autônomos para executá-lo.

Em 2014, três posições das equipes operacionais foram descontinuadas de modo a adequar a Ccaps a um nível orçamentário mais baixo, junto com demais medidas de contenção de despesa. 


\section{RESULTADOS}

Mesmo com todos os cortes de despesas e de pessoal, os resultados continuaram piorando. "Sempre planejamos três cenários para nosso próximo ano - otimista, moderado e pessimista. 2016 tem sido um desafio, pois estamos apontando para o pessimista", disse o CEO da Ccaps. Após um ano mais equilibrado em 2015 em função dos cortes do ano anterior, 2016 começou com menos pedidos de trabalho e, com o aviso antecipado de descontinuidade de um dos maiores clientes. Segundo Fabiano, "só o fim deste contrato vai significar uma queda de mais de $15 \%$ da nossa receita em bases anuais. Já temos uma clara indicação de resultado negativo para este ano".

Nos primeiros anos da empresa era possível atingir cerca de $25 \%$ de EBITDA. Com o forte crescimento da receita em 2008/ 09, a margem retornou para perto deste patamar, mas perdeu fôlego novamente e a direção da empresa preocupava-se que os baixos retornos impossibilitassem a Ccaps de fazer novos investimentos, seja em tecnologia, seja na manutenção dos atuais clientes ou na conquista de novos. Se a tendência continuasse sendo de queda, a própria existência da empresa ficaria ameaçada.

\section{PREPARAÇÃO PARA O CONSELHO}

Já com as receitas e despesas do primeiro e segundo trimestres de 2016 executadas, a área de Finanças deixara claro que um novo ajuste teria de acontecer antes do final do ano para que a Ccaps não voltasse a ter prejuízo. Fabiano decidiu então trocar algumas ideias com seu diretor mais experiente e com a equipe de negócios para se preparar melhor para a reunião de Conselho.

O Diretor de Produção, Cassius Figueiredo, já era um reconhecido profissional do mercado de localização, com 22 anos de trabalho, sólida formação em Ciência da Computação, um mestrado em Administração e outro em Matemática Aplicada. Antes da Ccaps, ele passara por alguns dos maiores MLVs globais, onde trilhou uma carreira ascendente até administrar toda a área de produção. Estava vinculado à Ccaps desde 2007, sendo o segundo no comando da empresa, gerindo-a nas ausências do CEO. 
Cassius já fazia parte do Conselho da empresa há alguns anos e conhecia bem os desafios. Fabiano o encontrou na sala de reuniões, terminando de avaliar alguns dos novos fornecedores externos que seriam usados nos trabalhos de localização da Ccaps.

- Cassius, fechamos os números para a reunião do Conselho e queria te ouvir sobre o momento do mercado...

- Bem, Fabiano, como temos nos falado, acredito que há uma mudança dramática em curso, que vai além das dificuldades econômicas do Brasil. Por um lado, alguns tradutores independentes se qualificaram e já fazem trabalhos para clientes potenciais nossos a um custo a que não podemos chegar, pois eles não têm nosso overhead. Por outro, os próprios clientes investiram em tecnologia e têm usado Machine Translation e memórias de tradução para baratear seus projetos. Além disso, os programas gigantescos a serem localizados já foram terminados, agora há apenas adições ou novos aplicativos, que não geram projetos grandes.

- Concordo com você. E tudo isto se soma à recessão e à perda de um dos nossos maiores clientes, o que vai nos obrigar a tomar novas medidas de contenção este ano. Gostaria que você pensasse que tipo de cortes podemos fazer na sua área, que é a maior da Ccaps, e me desse um retorno o mais breve possível. Estou discutindo o mesmo com as outras áreas.

- Posso te dar um retorno agora mesmo. Como nosso negócio está ficando cada vez mais comoditizado, minha recomendação é uma dramática mudança de estrutura, eliminando os salários mais altos para permitir à Ccaps sobreviver na crise. Falando contra mim mesmo, mas no espírito de amizade e confiança que sempre tivemos, se eu estivesse no seu lugar, eu me demitiria. Não faz sentido manter um diretor de produção caro como eu quando há tão pouco negócio hoje no nosso mercado.

Fabiano volta à sua sala ainda mais preocupado e com a cabeça latejando. Ele sabia que seu diretor de Produção tinha razão. Cassius era um 
"luxo" que a Ccaps talvez não pudesse mais manter, mas abrir mão do seu conhecimento e seu domínio do setor de localização, muito superior ao de qualquer outro gestor na empresa, poderia ser um "tiro no pé".

\section{NOVOS NEGÓCIOS}

Ele chama então o jovem coordenador de Desenvolvimento de Negócios da Ccaps, Raian Pollock, para entender o andamento dos diálogos com os muitos clientes potenciais da empresa. Trabalhando na Ccaps há dois anos, Raian avançara de estagiário a chefe da área de vendas em pouco tempo. Fabiano acreditava que Raian era um talento em relacionamento com clientes e, com apenas 20 anos de idade e ainda cursando a universidade, ele trazia o melhor da chamada geração millenium para a empresa - muita vontade de enfrentar desafios e a capacidade de pensar nas diferentes áreas com uma visão inovadora. Juntos, eles haviam criado uma nova ferramenta automatizada de aquisição de clientes, que atingia um grupo imenso de profissionais com interesse em localização por uma fração do investimento anterior.

- Raian, por favor, me dê uma posição atualizada dos clientes atuais e dos muitos leads que temos adquirido no mercado.

- Sob o ponto de vista de satisfação dos clientes globais, continuamos no topo, somos os líderes de qualidade na América Latina. O mercado nacional continua valorizando menos a Ccaps, pois este é o mercado focado em preços baixos que você conhece. Implantamos novos processos, mas ainda temos custos mais altos que a maioria dos concorrentes. Mesmo assim, temos fechado novos clientes a cada semana!

- Verdade. Infelizmente são na maioria clientes pequenos que ocupam muito tempo dos nossos gerentes de produção e geram um resultado baixo.

- Fabiano, não há dúvidas de que precisamos investir mais em tecnologia. Só com a automação total desses processos os clientes menores vão gerar um resultado positivo para a Ccaps. Como calculamos, dá para baixar os custos de produção em $30 \%$, o que vai direto para a margem. A pulverização do nosso mercado é 
um fato, vamos ter de gerar valor mesmo com esses pequenos negócios no longo prazo.

Raian acreditava que a inteligência artificial chegaria logo ao mercado de localização e mesmo à área de vendas. Para ele, a Ccaps deveria investir tudo o que pudesse na automatização de seus processos e se preparar logo para este mundo novo. Para Fabiano, esta era sim uma necessidade, mas a sobrevivência imediata da Ccaps dependia dos seus clientes tradicionais e parecia difícil avaliar a dinâmica deste novo mercado.

\section{DESAFIOS E FUTURO}

A Ccaps havia se consolidado em um mercado muito competitivo graças às credenciais de qualidade, confiabilidade e segurança da informação que construíra em seus anos de implantação. As novas tecnologias e a recessão pareciam estar mudando as regras de jogo do mercado de localização e as credenciais da Ccaps não mais pareciam suficientes. Era premente mudar a forma de trabalhar. Mas sem recursos excedentes tudo ficava mais difícil. A recessão do país havia dilapidado as reservas da empresa e seriam significativos os investimentos necessários para atualizar sua base tecnológica, em particular incorporando Machine Translation e Translation Management System, com a automação de fluxo de trabalho. Assim, não havia mais tempo a perder, as decisões de mudança precisavam ser tomadas hoje para que o impacto dos resultados decrescentes e a perda de um dos três maiores clientes da Ccaps pudessem ser enfrentados pela empresa ainda em 2016, assegurando um 2017 com resultados mais saudáveis.

Fabiano seguia para a reunião de Conselho dividido. Por um lado, era clara a necessidade de tomar medidas drásticas no curto prazo a fim de manter o equilíbrio da Ccaps. Por outro, diminuir ainda mais a estrutura da empresa, perdendo desta vez alguns de seus melhores profissionais, ou cortar todos os investimentos previstos, parecia um retorno ao passado, em lugar de preparar a Ccaps para o futuro. Ele esperava uma boa discussão e que tanto seus diretores quanto os dois membros externos pudessem ajudá-lo a repensar a empresa e a encontrar caminhos que permitissem à Ccaps reconquistar a boa posição de que desfrutava até há pouco tempo. 


\section{NOTAS DE ENSINO}

\section{OBJETIVOS EDUCACIONAIS}

O caso Ccaps é recomendado para disciplinas das áreas de Estratégia e de Inovação, ministradas em cursos de Administração de Empresas e Engenharia da Produção na graduação ou Gestão de Negócios na pós-graduação lato sensu, particularmente em sessões que abordem o impacto da inovação na sobrevivência de modelos de negócio estabelecidos. Este caso também poderia ser aplicado em sessões focadas na discussão de tipos de modelos de negócio, desde que sejam disponibilizadas pelo professor informações que viabilizem este uso alternativo, tais como exemplos de modelos de negócio aplicáveis a este segmento econômico, alguns dos quais utilizados por concorrentes da Ccaps, e as suas potenciais implicações estratégicas.

O caso procura fomentar o aprendizado dos alunos por meio de:

- Aprimoramento do conhecimento - impacto e desafios de inovações nas organizações, conforme apresentado na Teoria da Inovação Disruptiva, engendrada por Christensen (1997) e na Teoria da Ambidestria Organizacional, proposta de forma seminal por Duncan (1976). A primazia e a relevância de Duncan (1976) são reiteradas por O’Reilly e Tushman (2013). Ambos os conceitos foram aprofundados ao longo dos anos por diversos estudos acadêmicos.

- Construção de habilidades - criatividade e raciocínio abstrato; análise de dados e cenários; identificação de problemas, ameaças e oportunidades; e formulação de estratégias.

- Desenvolvimento de atitudes - receptividade a mudanças, amplitude e multidisciplinaridade intelectual.

Estes objetivos poderão ser alcançados pelas discussões suscitadas por este caso em sala de aula. Há dois desafios simultâneos para a sobrevivência da empresa retratada, um de curto e outro de longo prazo: uma das mais graves recessões da História do Brasil (ROSA, 2016), que modificou o panorama de competição na indústria e constitui o immediate issue (a que- 
stão imediata do caso), e as transformadoras mudanças de tecnologia no mercado de localização de software - que é o fundamental issue (a questão fundamental) a ser desvendado e enfrentado pelos alunos durante a análise e discussão do caso.

Por meio do processo indutivo inerente a casos-problema como este, os alunos deverão inferir os conceitos da Teoria da Inovação Disruptiva e da Ambidestria Organizacional e, sobretudo, articular as suas implicações teóricas e empíricas para vislumbrar alternativas estratégicas promissoras com o intuito de perenizar a Ccaps diante dos dois desafios citados.

O método do caso não demanda leituras prévias teóricas. No entanto, caso o professor prefira seguir um método híbrido que melhor se adeque às características da turma na qual discutirá este caso, ele poderá programar para esta sessão a leitura antecipada dos seguintes textos:

- Teoria da Inovação Disruptiva: capítulo 2 de Christensen (1997).

- Ambidestria Organizacional: O’Reilly e Tushman (2004).

\section{FONTES DE INFORMAÇÕES}

As informações utilizadas para a elaboração deste caso de ensino foram obtidas de fontes primárias e secundárias. As fontes primárias foram entrevistas com executivos da Ccaps: Fabiano Cid (Diretor Executivo), Cassius Figueiredo (Diretor de Produção) e Raian Pollock (Coordenador de Desenvolvimento de Negócios). Também foi realizado contato por escrito com o líder da Common Sense Advisory, principal empresa global de pesquisa de mercado e consultoria do segmento de localização, Don dePalma, Diretor de Estratégia e Fundador (Chief Strategist and Founder). As principais fontes secundárias foram o website e os relatórios anuais de 2011 a 2015 preparados pela Common Sense Advisory, os relatórios da empresa de consultoria em estratégia de negócios Blau Consulting para a Ccaps em novembro de 2013, o website da GALA (Globalization and Localization Association), os websites das principais empresas globais de localização e o da própria Ccaps e materiais internos da empresa, como relatórios trimestrais e anuais e dados de planejamento (protegidos por um non-disclosure agreement no que tange à proibição de uso externo de alguns dados de competição e financeiros). 


\section{QUESTÕES PARA DISCUSSÃO}

As questões propostas a seguir podem servir de base para as discussões que surgirão em sala de aula, guiando os alunos na descoberta e exploração de múltiplas abordagens para análise do fundamental issue do caso.

Estas questões derivam de diversas perspectivas (interna, externa, mercadológica e tecnológica) e seus problemas e soluções correlatos expostos por Yu e Hang (2010).

1. Quais são os principais aspectos e desafios dos ambientes competitivos atual e futuro da Ccaps?

2. Quais são as capacidades atuais da Ccaps e as que ela terá que desenvolver para sobreviver no futuro ambiente competitivo?

3. Quais ações estratégicas a Ccaps necessitará empreender para preencher a lacuna existente entre as suas capacidades atuais e futuras e, ao mesmo tempo, sobreviver em meio a uma das mais graves recessões da História do Brasil?

\section{PLANO DE ENSINO SUGERIDO}

Sugere-se a condução da discussão do caso seguindo a ordem das questões acima propostas.

Além das questões para discussão, a fim de nortear a preparação do caso de ensino por parte dos alunos são sugeridas a seguir algumas questões (assignment questions) relacionadas ao immediate issue. Estas perguntas podem ser entregues junto com o caso para leitura prévia ou em sala, imediatamente antes da discussão em pequenos grupos.

O fornecimento destas perguntas é facultativo, ou seja, não são essenciais para a discussão do caso. Sua aplicação deve ser decidida pelo professor de acordo com a sua avaliação do grau de maturidade da turma em questão.
A. O que a Ccaps necessita fazer com urgência para sobreviver?
B. Qual é o impacto das novas tecnologias para o negócio da Ccaps?
C. As ações já realizadas pela Ccaps ajudam no longo prazo?
D. O modelo de negócios da Ccaps é viável? 
A discussão em sala de aula com todos os alunos (plenária) pode ser iniciada com uma pergunta de abertura que aproxime o tema para a sua realidade cotidiana e, assim, motive o engajamento: "Quem nesta sala prefere utilizar um software em português e não em inglês ou em outro idioma estrangeiro?" seguida por outras de "aquecimento" e ainda sob a ótica do consumidor final, como "Alguém gostaria de explicar as suas razões?". Para enriquecer visualmente e tangibilizar a discussão, como recurso adicional pode-se projetar duas telas iguais do mesmo software mas em idiomas distintos (em português e inglês).

Após este início, espera-se que os alunos estejam com o "estado de espírito" adequado para o professor abordar a primeira questão de discussão.

Questão 1 (referente à lâmina 1 do Plano de Quadro): Quais são os principais aspectos e desafios dos ambientes competitivos atual e futuro da Ccaps?

Esta questão e seus desdobramentos incentivarão os alunos a analisar de forma multidisciplinar, sobretudo sob a ótica estratégica, os desafios imediatos e de longo prazo para a sobrevivência da Ccaps.

Com isto, criam-se as condições para discutir com os alunos os conceitos subjacentes à Ambidestria Organizacional, definida por Raisch e Birkinshaw (2008) como a capacidade de uma organização de conciliar a eficácia e eficiência no presente com a adaptação às mudanças no seu ambiente externo que serão determinantes para o seu futuro. O caso Ccaps ilustra esta questão. A empresa necessita adequar seus custos atuais para gerar recursos que a permitam investir nas tecnologias e na capacitação da equipe que possibilitarão a ela continuar competitiva no mercado de localização de software ou mesmo abrir novas linhas de atuação.

Ao estimular que na discussão em sala surjam as ameaças atuais e futuras para a Ccaps, suscitadas pela MT e potencializadas pelas redes neurais e a inteligência artificial, a essência da Teoria da Inovação Disruptiva também emergirá. Esta consiste, sinteticamente e conforme conceituado por Christensen (1997), em desdobramentos de tecnologias que fornecem 
"valores" diferentes das tecnologias mainstream e são inicialmente inferiores nas dimensões de desempenho mais importantes para os clientes que predominam naquele momento no mercado. Assim, o predomínio atual e a melhor qualidade de tradutores humanos deverão ser superados pela MT em futuro não muito distante, criando disrupção e mudanças relevantes no mercado.

Transition question para "Questão 2": Vocês acham que a equipe da Ccaps está posicionada para enfrentar o futuro?

\section{Questão 2 (referente à lâmina 2 do Plano de Quadro): Quais são as capa- cidades atuais da Ccaps e as que ela terá que conquistar para sobreviver no futuro ambiente competitivo?}

A transition question proposta (que deve ser adaptada ao estilo do professor que conduzirá a discussão do caso) permite efetuar a transição da análise do meio externo (ambiente competitivo) para a análise do meio interno (capacidades da Ccaps). Como consequência, os pilares e as lacunas para a operacionalização por parte desta da Ambidestria Organizacional são vislumbrados pelos alunos. Aqui também é reforçada a ameaça representada pela Inovação Disruptiva à existência da Ccaps.

Para tanto, na condução das discussões o professor poderá incentivar a conexão pelos alunos entre as capacidades a serem desenvolvidas pela Ccaps e a questão fundamental, que é a tecnologia disruptiva. Tushman e O’Reilly (2002) propuseram o conceito de "organizações ambidestras" como uma solução para lidar com inovações de descontinuidade, partindo do princípio de que mesmo sem uma estrutura isolada e autônoma, uma organização pode se equipar com recursos, processos e valores para gerenciar a sua sustentabilidade e as inovações disruptivas. Além disso, de acordo com Yu e Hang (2010), a Ambidestria Organizacional é um aspecto da perspectiva interna das organizações com características tanto inibidoras quanto habilitadoras de Inovações Disruptivas.

A evolução do TMS, com a automação progressiva dos processos, poderá aumentar a produtividade da Ccaps. Conforme a proposta do Coor- 
denador Raian Pollock, a empresa poderia baixar seus custos de produção em $30 \%$ com a automação de fluxos de trabalho. Este investimento, de imediato, poderia reverter a queda de EBTIDA mencionada no caso.

Adicionalmente, a MT será essencial para atender os clientes a custos mais baixos e manter a empresa competitiva, além de prepará-la para a inovação disruptiva, que é a passagem de tradutores humanos para a plena tradução computadorizada. A adoção da tecnologia de MT permitirá à empresa se preparar para esta mudança e se capacitar para enfrentar o novo mercado. Há uma tendência de que no futuro grandes empresas (clientes atuais de serviços de localização e tradução) adquiram ferramentas de MT de alta qualidade e empresas de porte reduzido optem pelo uso de ferramentas gratuitas e aprimoradas (como, por exemplo, o Google Tradutor). Assim, mesmo em longo prazo poderá restar um nicho de mercado (ainda que reduzido) para a Ccaps.

A Ccaps deverá se preparar para trabalhar com um contingente menor de colaboradores, tanto funcionários quanto terceirizados, e possivelmente deverá reposicionar seu negócio central, necessitando de outras capacidades profissionais. Os profissionais necessários para este novo mercado serão os que dominarem o uso da tecnologia e os que forem capazes de desenvolver relacionamentos continuados com os clientes. De certa forma, as competências necessárias passam a ser mais alinhadas com marketing, vendas e engenharia de software e menos com tradução.

Transition question para “Questão 3”: E agora, o que a Ccaps precisa fazer?

Questão 3 (referente à lâmina 3 do Plano de Quadro): Que ações estratégicas a Ccaps necessitará empreender para preencher a lacuna existente entre as suas capacidades atuais e futuras e, ao mesmo tempo, sobreviver em meio a uma das mais graves recessões da História do Brasil?

A pergunta de transição proposta visa guiar os alunos para a discussão do fundamental issue com alternativas estratégicas promissoras para perenizar a Ccaps via aplicação dos conceitos de Ambidestria Organizacional. Espera-se que ao longo da discussão surjam os princípios de exploitation - associa- 
da a atividades como "refinamento, eficiência, seleção e implementação" - e de exploration - que se refere a noções como "busca, variação, experimentação e descoberta" - conforme formulados por March (1991).

Qualquer conjunto de ações propostas pelos alunos para enfrentar a situação possivelmente os levará a pensar na adequação da estrutura de custos da empresa e na busca de novos caminhos, seja por meio de aquisição de tecnologia pronta ou no seu desenvolvimento mediante parcerias empresariais ou acadêmicas. No entanto, os custos da empresa não eram adequados ao seu nível de receita na data do caso. Além de não gerar resultados suficientes, a baixa margem impossibilitava os investimentos necessários para o futuro.

Portanto, o grande desafio para a Ccaps é empreender simultaneamente duas transformações vitais para a sua sobrevivência imediata e futura, que se tornam ainda mais desafiadoras e complexas por serem distintas na sua natureza e no seu horizonte de tempo. A mais imediata delas é tornar o seu modelo de negócios atual mais eficiente, flexível e com uma base de clientes ampliada. A outra transformação, de longo prazo mas que não pode ser postergada em função da evolução acelerada da Inteligência Artificial nos mercados de localização e tradução, consiste na evolução muito mais radical no seu modelo de negócios. Nesta última, a Ccaps necessita tornar-se uma empresa de alta tecnologia com sócios e parceiros estratégicos que proporcionem recursos financeiros e tecnológicos de vulto.

O objetivo último da Ccaps deve ser tornar-se, por meio dessas duas transformações vitais e de acordo com a tipologia preconizada por Karrer e Fleck (2015), uma "organização ambidestra a longo prazo", assegurando a sobrevivência da empresa de forma perene.

\section{PLANO DE QUADRO (BOARD PLAN)}

O quadro sugerido visa facilitar a estruturação do registro pelo professor das análises que surgirem em sala de aula como produto das questões para discussão acima propostas. A intenção é facilitar a condução, sem inibir a desejada criatividade dos alunos e a sua pluralidade de visões e abordagens. O Plano de Quadro deverá funcionar como referência para os 
registros possíveis e desejáveis a serem feitos pelo professor no quadro da sala como resultado das discussões, ou seja, é um "plano de voo" flexível.

Sugere-se que o quadro seja preenchido da esquerda para a direita, em conformidade com a sequência lógica para o alcance e discussão do fundamental issue do caso. Isto não deve ser encarado com rigidez, pois é provável que as discussões em sala levem à necessidade do professor registrar alguns pontos adicionais pertinentes a alguma lâmina do quadro que já havia sido previamente explorada e preenchida.

O quadro é único, porém segmentado nas três lâminas detalhadas a seguir e correspondentes às questões para discussão:

\section{Lâmina 1 ("Ambiente Competitivo"), correspondente à questão para discussão 1 .}

\begin{tabular}{|c|c|}
\hline $\begin{array}{l}\text { Ambiente Atual } \\
\text { Tradução é relevante componente dos } \\
\text { serviços de localização, com alto custo } \\
\text { de execução (freelancers, TI, revisão, } \\
\text { gerenciamento). } \\
\text { Mercado com LSPs com diferentes atu- } \\
\text { ações (MLVs, SLVs e RLVs) e algumas } \\
\text { grandes empresas com equipes pró- } \\
\text { prias ("primarizadas”). Pulverização! } \\
\text { Mercado global com crescimento ro- } \\
\text { busto. } \\
\text { Mercado brasileiro com redução signi- } \\
\text { ficativa e forte crise. } \\
\text { Concorrência forte, pulverizada e hete- } \\
\text { rogênea (inclusive de freelancers). } \\
\text { Uso intensivo de tecnologia (TMS e } \\
\text { MT). } \\
\text { MT constituindo uma ameaça crescen- } \\
\text { te (tendência de automação). }\end{array}$ & $\begin{array}{l}\text { Ambiente Futuro } \\
\text { - Tradução automatizada a baixo } \\
\text { custo por MT e outras tecnolo- } \\
\text { gias (de inteligência artificial em } \\
\text { especial). } \\
\text { - Tecnologia como diferencial } \\
\text { competitivo ainda maior. } \\
\text { - Mercado "comoditizado" e re- } \\
\text { duzido pela automação generali- } \\
\text { zada e pela "primarização". } \\
\text { - Protagonismo de aplicativos de } \\
\text { pequeno porte em substituição } \\
\text { a grandes softwares reduz ainda } \\
\text { mais o mercado de localização. } \\
\text { Demanda continuamente menor. } \\
\text { - Novos mercados para localiza- } \\
\text { ção, mais especializados (de "ni- } \\
\text { cho") e ainda mais pulverizados. }\end{array}$ \\
\hline
\end{tabular}




\section{Lâmina 2 ("Capacidades da Ccaps"), correspondente à questão para discussão 2.}

\begin{tabular}{|l|l|}
\hline \multicolumn{1}{|c|}{ Capacidades Atuais } & Capacidades Necessárias Futuras \\
- Equipe híbrida (própria e terceirizada). & - Eficiência em custos. \\
- Marca: RLV focada na América Latina. & - Equipe mais flexível e com pre- \\
- Liderança em qualidade na América & dominância de especialistas em \\
Latina. & vendas e TI. \\
- Confiabilidade e segurança da infor- & - Flexibilidade maior em qualidade \\
mação. & e preço. \\
- Baixo uso de tecnologia. & - Base de clientes mais diversificada. \\
- Foco em clientes de grande porte. & - Uso mais intensivo de tecnologia. \\
\hline
\end{tabular}

\section{Lâmina 3 ("Plano de Ação da Ccaps"), correspondente à questão para discussão 3.}

\begin{tabular}{|c|c|}
\hline $\begin{array}{l}\text { Ações de Curto Prazo } \\
\text { - Reduzir custos fixos, em } \\
\text { especial com pessoal. } \\
\text { - Diversificar base de } \\
\text { clientes, sobretudo em } \\
\text { nichos não atendidos } \\
\text { atualmente. } \\
\text { - Intensificar o uso de tec- } \\
\text { nologia e processos para } \\
\text { diminuir custo e tempo. } \\
\text { - Implantar modelo de } \\
\text { precificação mais flexí- } \\
\text { vel. }\end{array}$ & $\begin{array}{l}\text { Ações de Longo Prazo } \\
\text { - Tornar-se uma empresa de alta tecnologia com } \\
\text { uso de ferramentas sofisticadas de tradução e au- } \\
\text { tomação de fluxo de processos. } \\
\text { - Buscar sócios e parceiros estratégicos que pro- } \\
\text { porcionem recursos financeiros de vulto. } \\
\text { - Buscar parcerias tecnológicas com instituições } \\
\text { acadêmicas e com outras empresas. } \\
\text { - Priorizar o nicho de mercado constituído por em- } \\
\text { presas que não adquirirão ferramentas de MT de } \\
\text { alta qualidade (como tendem a fazer clientes atu- } \\
\text { ais de serviços de localização e tradução) e nem } \\
\text { utilizarão ferramentas gratuitas (tendência de } \\
\text { empresas de porte reduzido). } \\
\text { - Implantar modelo de precificação ainda mais fle- } \\
\text { xível. }\end{array}$ \\
\hline
\end{tabular}




\section{ENCERRAMENTO DA DISCUSSÃO DO CASO}

Uma alternativa para o encerramento da discussão do caso poderia ser a proposição de uma situação desafiadora e inovadora mais abrangente. Uma sugestão seria discutir o impacto que o desenvolvimento da Inteligência Artificial (IA) terá sobre as empresas, as profissões e a vida das pessoas. O setor de localização está sendo totalmente transformado a partir da IA, cujo poder tem sido alavancado vertiginosamente pela evolução dos algoritmos e pelas redes neurais computacionais interligadas pela Internet. Prevê-se que, em alguns anos, um software fará o trabalho de tradutores e engenheiros tão bem quanto estes, mas muito mais rápido. Para que os alunos continuem desenvolvendo seu pensamento depois da discussão, pode-se sugerir a leitura da matéria de O Globo "Especialista alerta para perigo de avanço de inteligência artificial", que expõe o pensamento do professor titular de economia da USP, Ricardo Abramovay, sobre o futuro alcance da Inteligência Artificial (IA) e seu impacto nas empresas, no emprego e nas vidas das pessoas (SETTI, 2016).

Um caso de ensino não supõe respostas únicas ou "corretas". Encerrar o caso com uma questão desafiadora como esta possivelmente instigará os alunos a pensar mais sobre o tema fora da sala de aula.

\section{O QUE ACONTECEU DEPOIS}

Tipicamente na cultura brasileira, os alunos demonstram curiosidade em relação aos desdobramentos do caso. Assim, apresentamos a seguir um relato dos fatos ocorridos após a data de encerramento da narrativa do caso.

Na reunião do Conselho, o CEO apresentou as previsões para o restante de 2016 e, pressionado pela situação financeira e pelos conselheiros externos, sugeriu uma redução drástica na folha funcional da empresa e o desenvolvimento de estratégia de diversificação e investimento em tecnologia. Os conselheiros concordaram com a avaliação e aprovaram por consenso este caminho. Posteriormente, junto com seu sócio, Fabiano Cid eliminou um dos níveis da organização, a diretoria imediatamente abaixo da sua posição (seguindo e ampliando a recomendação de Cassius Figueiredo). Assim, os gerentes ou coordenadores de equipe passaram a se 
reportar diretamente a ele e os maiores salários foram eliminados, promovendo uma economia na folha que só seria possível de outra forma com a eliminação de cerca de 10 funcionários operacionais. A empresa também tomou outras medidas de contenção de custos, sendo a mais significativa a mudança de seu escritório, que resultou em uma redução de $30 \%$ neste custo, mesmo ampliando a área da empresa, efeito da queda de aluguéis em decorrência da grave recessão no Brasil.

Ao final de 2016, no entanto, ainda não havia recursos para investimentos, pois o custo das demissões de funcionários graduados e da mudança de escritório superavam o da manutenção da antiga estrutura. Porém, a expectativa era avançar com uma plataforma mais enxuta e ágil, liberando recursos e trabalhando em novos projetos rapidamente. Em paralelo à mudança e às demissões, foi desenvolvido um plano estratégico de diversificação de serviços e de investimento em tecnologia para implantação no ano seguinte. No primeiro trimestre de 2018 foi feito um acordo com uma empresa canadense, que adicionava a localização para mercados de idioma inglês e francês com disponibilidade de caixa para os investimentos necessários, permitindo uma ampliação significativa nos investimentos em tecnologia e na captação de clientes diretos.

As ações implementadas pela Ccaps não constituem a única solução possível, mas é bastante provável que surja como um dos caminhos ao final da sessão em aula. 


\section{REFERÊNCIAS}

CHRISTENSEN, C. Exploring the limits of the technology S-curve. Part I: component technologies. Production and Operations Management, 1.4: 334-357, 1992.

CHRISTENSEN, C. M. The Innovator's Dilemma: When New Technologies Cause Great Firms to Fail: Boston, MA: Harvard Business School Press, 1997.

DUNCAN, R. The ambidextrous organization: Designing dual structures for innovation. In R. H. Killman, L. R. Pondy, \& D. Sleven (Eds.), The Management of Organization, 1: 167188. New York: North Holland, 1976.

KARRER, D.; FLECK, D. Organizing for ambidexterity: a paradox-based typology of ambidexterity-related organizational states. BAR-Brazilian Administration Review, 12(4), 365-383, 2015.

MARCH, J. G. Exploration and exploitation in organizational learning. Organization Science, 2: 71-87, 1991.

O’REILLY, C. A.; TUSHMAN, M. L. Organizational ambidexterity: Past, present, and future. Academy of Management Perspectives, 27(4), 324-338, 2013.

O'REILLY, C. A.; TUSHMAN, M. L. The Ambidextrous Organization. Harvard Business Review, April 2004.

RAISCH, S.; BIRKINSHAW, J. Organizational ambidexterity: Antecedents, outcomes, and moderators. Journal of Management, 2008.

ROSA, B. Para Meirelles, Brasil terá pior recessão desde 1901. O Globo, 03/08/2016. Disponível em: <http:/ / oglobo.globo.com/economia/negocios/para-meirelles-brasil-tera-pior-recessao-desde-1901-19844142\#ixzz4RVH2SmhJ> . Acesso em: 6 dez. 2016.

SETTI, R. Especialista alerta para perigo de avanço de inteligência artificial. O Globo, 27/11/2016. Disponível em: <http:/ / oglobo.globo.com/economia/especialista-alerta-para-perigo-de-avanco-de-inteligencia-artificial-20547860 >. Acesso em: 27 nov. 2016.

TUSHMAN, M. L.; O’REILLY, C. A. Winning through Innovation: A Practical Guide to Leading Organizational Change and Renewal. Boston, MA: Harvard Business School Press, 2002.

YU, D.; HANG, C. C. A reflective review of disruptive innovation theory. International Journal of Management Reviews, v. 12, n. 4, p. 435-452, 2010. 


\section{DADOS DOS AUTORES}

\section{MARCO F. SIMÕES-COELHO marco.simoes@coppead.ufrj.br}

Mestre em Administração pelo Daniels College of Busines/University of Denver/EUA Instituição de vinculação: Coppead - Universidade Federal do Rio de Janeiro Rio de Janeiro/RJ - Brasil Áreas de interesse em pesquisa: Sustentabilidade; Negócios Internacionais; Legitimidade; Motivação.

Rua Pascoal Lemme, 355 Cidade Universitária Rio de Janeiro/RJ 21941-918

\section{GISELA SENDER gisela.sender@coppead.ufrj.br}

Mestre em Administração pelo Coppead/UFRJ

Instituição de vinculação: Coppead - Universidade Federal do Rio de Janeiro

Rio de Janeiro/RJ - Brasil

Áreas de interesse em pesquisa: Comportamento Organizacional; Gestão de Recursos Humanos; Estratégia.

\section{RONALDO ANDRADE DECCAX ronaldo.deccax@coppead.ufrj.br}

Mestre em Administração pelo Coppead/UFRJ

Instituição de vinculação: Coppead - Universidade Federal do Rio de Janeiro Rio de Janeiro/RJ - Brasil

Áreas de interesse em pesquisa: Finanças Comportamentais; Julgamento e Tomada de Decisão.

\section{VICTOR MANOEL CUNHA DE ALMEIDA valmeida@coppead.ufrj.br}

Doutor em Administração pelo Coppead/UFRJ

Instituição de vinculação: Coppead - Universidade Federal do Rio de Janeiro

Rio de Janeiro/RJ - Brasil

Áreas de interesse em pesquisa: Marketing. 